\title{
Guidelines for developing agricultural information portals in the Southern African Development Community Region (SADC)
}

\section{J. Chisenga}

Food and Agriculture Organization of the United Nations

Regional Office for Africa

Accra, Ghana

chisenga_j@yahoo.co.uk

\section{P.A. van Brakel}

Department of Information and Knowledge Management

University of Johannesburg

Johannesburg, South Africa

pavb@rau.ac.za

\section{Contents}

1. Introduction

2. Portals

2.1 What is a portal?

3. Agricultural information portals

3.1 Application of agricultural information portals (AIP)

3.2 Components of AIP

4. Portal development guidelines

4.1 Purpose of the guidelines

4.2 Limitation of the guidelines

4.3 General guidelines

4.4 Specific guidelines

5. Conclusion

6. References

Key words: Portals, agricultural portals, information dissemination, portal development guidelines 


\section{Introduction}

The Internet and the Web have become a source of agricultural information for many people, including researchers working in agricultural research organizations. According to Besemer, Addison and Ferguson (2003:2), the Web has changed the information landscape in the field of agriculture and natural resources. The relatively small investment required to set up a Web site enables a great many institutions to become instant information providers. This has resulted in some problems noted by Besemer et al. (2003:2) who state that:

'The trend of proliferation of Websites has continued for a number of years. As a result, the current system of agricultural information services is at times rather incoherent, and those in search of high quality information often have difficulty separating the wheat from the chaff. There are a great number of services, but potential users often have problems finding and accessing relevant information in usable formats.'

There are just too many Web sites that point to sources of information rather than the information itself, making it difficult for information end-users, such as researchers working in agricultural research organizations, to get the information they are really looking for in good time. This is a problem that could be addressed by developing more portals for agricultural research information.

\section{Portals}

Portals have become one of today's biggest Web trends. Corporate organizations are setting up portals to attract customers to their Web sites and, in some cases, to use them as mediums for business-to-business (B2B) e-commerce tools (O'Leary 2000). Staff and clients of corporate organizations are accessing various types of content, developed within the organization, in internal and external information resources and services via their corporate Web sites. Although portals are largely being deployed in corporate organizations, they appear to have great potential and useful applications in other types of organizations, such as agricultural research organizations, where consumption and generation of information and knowledge are among their major activities.

The underlying principle of the portal model of information management is that the provision of access to Web-based information resources and services should correlate to the information needs of end-users. Furthermore, a portal-based information system can monitor the end-user's use of the available resources and services. This enables the system to aggregate various information services and resources and make them available to the user via the portal. Overall, the portal model of information management and distribution, in addition to its potential for the reduction of information overload in organizations, also has great potential for use in the provision of information services where information specialists target individual end-users.

\subsection{What is a portal?}

There is no generally accepted definition of a portal, and this is illustrated by the following definitions given by various authors:

'Application that provides a personalised and adaptive interface enabling people to discover, track, and interact with other people, applications, and information relevant to their interests' (Morrison 2000). 
'Web site that provides an entry point to the Internet, and offers value-added services such as directories, searching, information news, and links to related Web sites' (Rowley 2000:62).

"' Supersite " on the Internet that provides a comprehensive entry point for a huge array of resources and services ' (Berkman 2000).

'Web address destination to which people with some common set of characteristics, interests, or needs go to gather information, interact with data, experience entertainment, exchange thoughts, or conduct transactions' (Hurwitz 2001:110).

It should also be noted that there are different types of portals, with different features, thus making it difficult to have a definition that is applicable to all types of portals. Although there is no generally accepted system for classifying portals, four broad categories of portals can be identified:

- Web portals: A Web site or service that offers a broad array of resources and services, such as e-mail, forums, search engines and on-line shopping malls (Webopedia 2001). These portals are designed to act as gateways to the Internet, and they provide access to a wide range of Web-based resources and services, including Internet search and navigation, free Web-based e-mail facilities, free home pages hosting, entertainment information, stock market information, foreign currency exchange information, customized news and weather information, sports, horoscope, planners and calendars, real-time chat facilities, message boards, original content on various subjects, shopping facilities; and much more. Examples of Web portals include Excite, Lycos, MSN, Netscape Netcenter, Yahoo! and American Online (AOL).

- Vertical portals: Also known as niche portals or vortals, vertical portals have a tightly focused information content area geared towards a particular category of audience. There are several examples of vertical portals accessible on the World Wide Web. The Vertical Portals.Com main directory available at http://www.verticalportals.com lists around 150 vertical portals on various subject areas such as animals, art, beauty, computers, entertainment, food, music, news, real estate, sports, travel vehicles and many more. Examples of vertical portals include ZDNet.com and Soccernet.com.

- Affinity portals: These are portals aggregating information geared towards specific community groups, specific ethnic groups, specific age groups, alternative lifestyles, religions, and other groups that are perceived to form a community or market. By targeting specific groups, affinity portals also include the kind of features that Web users would find on Web portals, including e-mail, shopping, chat areas, news and financial information, among other things. A very good example is WeMedia.Com available at http://www.wemedia.com. This portal targets people with disabilities and was launched in 1999 by a magazine publisher, We Media, to coincide with the United Nations International Day of Disabled Persons (Hu 1999).

- Enterprise information portals (EIPs): These portals largely concentrate on harnessing internal corporate information resources and selected external information resources for the benefit of the organization. In general, EIPs provide access to information resources on the corporate intranet and to selected information resources available via the Web (CNET Networks 1999). EIPs are generally located behind firewalls and are not accessible to the outside public.

In spite of the absence of a universally accepted definition of a portal, a suitable definition can be formulated after having examined the features of portals, or what portals are supposed to achieve. 
According to Morrison, Buckey and Cappo (1999:9), a portal allows users to:

- Discover information quickly instead of browsing for it

- Have consolidated access to applications

- Be part of a community

- Have access to critical resources.

Ethridge, Hadden and Smith (2000:13-14) identify and discuss several distinguishing features of portals:

- Portals facilitate the discovery of people, organizations and content in a meaningful context

- Portals are secure, offering user authentication, credential mapping and sensitive data encryption

- Portals are personalized, proactively providing customized desktops based on the user's role in the community or enterprise

- Portals are adaptive

- Portals are single points of service, providing a framework for accessing multiple heterogeneous data stores, including enterprise databases, e-mail and other multimedia resources.

Morrison (2000) groups the major characteristics of portals into six unique features:

- Personalization for end-users

- Organization of the desktop

- Resource division

- Tracking activities

- Access and display of stored data

- Location of important people and things.

Taking into account the above observations, the following work definition, based on Morrison's (2000) definition of a portal, was formulated for this article:

A portal is a Web-based application accessed over the Internet, intranet or extranet that provides a personalized and adaptive interface, enabling users to discover, track and interact with other people, applications, services and information relevant to their interests.

The above definition captures the essence of portals, which is to provide access to personalized information resources and services, and at the same time support various information access and management tools through a Web-based interface.

\section{Agricultural information portals}

In an extensive research project covering the SADC countries, the necessity of identifying an agricultural portal was felt (Chisenga 2004). Based on this research, an agricultural information portal(AIP) was defined as:

'A Web-based application accessed over the intranet or extranet that provides a personalised and adaptive interface enabling agricultural researchers to discover, track, and interact with colleagues and other people, software applications, information resources, services and tools relevant to their research 
interests and work' (Chisenga 2004:226).

An agricultural information portal is therefore a one-stop point of access for researchers to agricultural information resources, services, tools and facilities, and includes virtual conferencing, instant messaging systems, virtual team workspace, discussion forums, document sharing, and electronic white boarding.

\subsection{Application of agricultural information portals}

The use of AIPs in the provision of access to digital information services in agricultural research organizations has several advantages. Portals can provide increased functionalities and improved access to information resources and services to researchers within the organization. AIPs could also enable researchers, through a single user interface, to:

- Share information and knowledge with colleagues within and outside the organization

- Collaborate on research projects with colleagues within and outside the organization

- Manage and track the progress of various research projects being implemented by the organization

- Access various information resources such as bibliographic and full-text databases, images, and video clips generated within the organization, services and tools relevant to agricultural research work, and information resources from external sources and organizations (Chisenga 2004:226-228).

\subsection{Components of AIP}

An AIP consists of the features outlined below and graphically illustrated in Figure 1. These features were identified in an extensive investigation into the nature of agricultural portals in the SADC countries (Chisenga and Van Brakel 2004:123-135) and developed further with the help of the intra net reference model proposed by CIO Communications (2001). The features are as follows:

- Portal end-users: These are the target users of the portal facilities and resources. In some cases, some end-users could also be content developers. In agricultural research organizations, researchers are expected to be the major users of AIPs.

- Portal developers: This group mainly consists of information technology specialists or external firms and consultants involved in the development and maintenance of the portal.

- Portal development tools: Tools consist of portal development software, standards and guidelines.

- Portal content developers: This group includes both internal and external content developers and providers. Therefore, external online database suppliers, publishers of electronic journals, and many others are included in this category.

- Portal security: These are features that allow or restrict access to the portal content, and control publishing (adding, modifying and deleting) of content on the portal.

- Portal content publishing and management tools: These features are to ols and software used to generate and publish content on the portal.

- Content management and use policy: These are overall guidelines for publishing, managing and using content via the portal.

- Portal discovery tools: Various tools are used for retrieving content on the portal, for example internal search engines and taxonomy.

- Portal user tools: These tools consist of, for example, Web browsers, help applications and hardware used to facilitate access to the portal resources.

- Integration with the Internet: When developing an agricultural information portal, it is economical and efficient not to replicate content already available on other public Web 
sites. If appropriate content is available on other public Web sites that support or fit into the goals and objectives of the AIP, links should be established to the content so that users of the AIP have direct access.

- Portal user support: This refers to the assistance given to users to enable them to make effective use of the portal resources, including technical support and training.

- Portal content: This consists of the various contents and facilities available on the portal.

Figure 1 Major features of an agricultural information portal

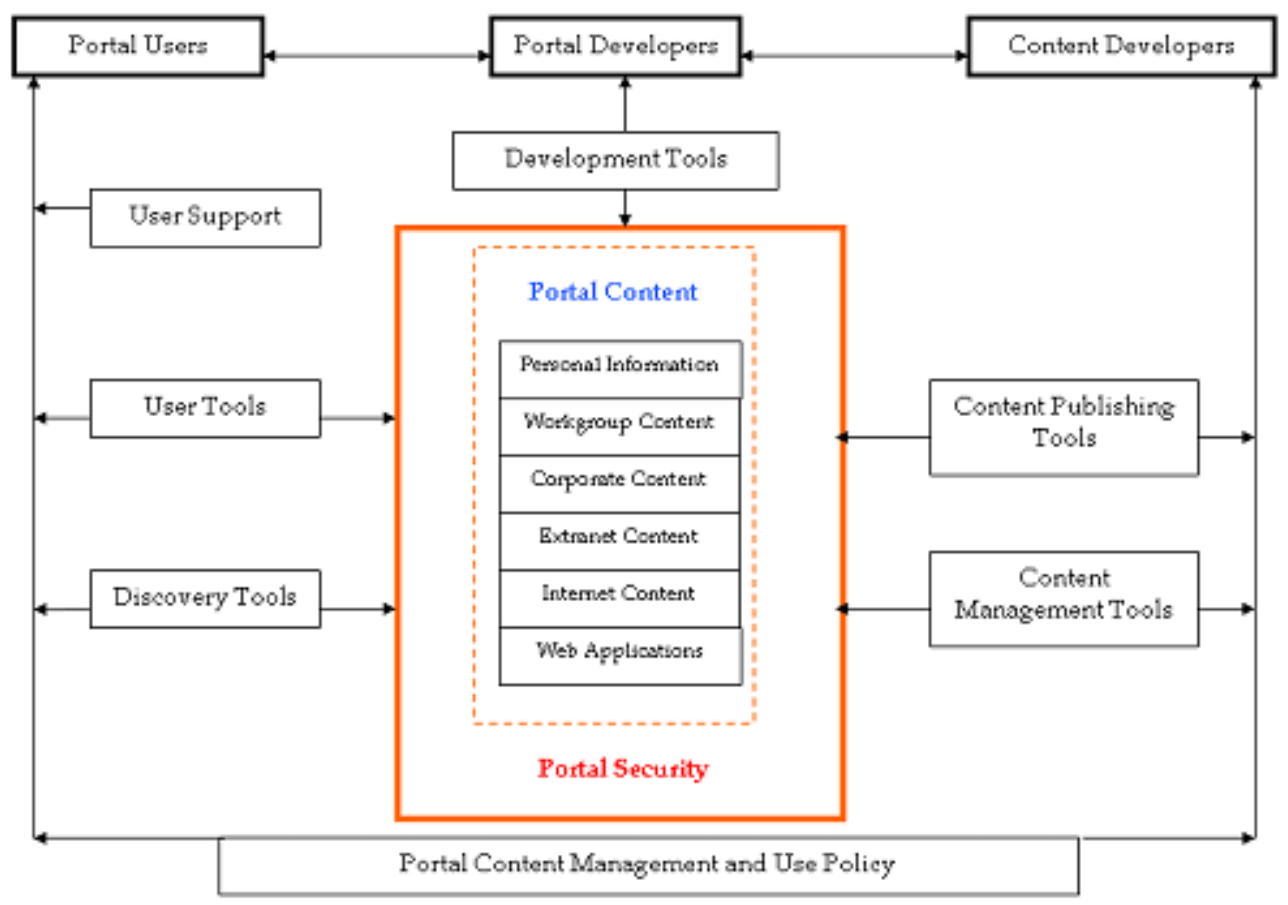

\section{Portal development guidelines}

As indicated above, portals are Web-based information systems designed to achieve a set of defined objectives. These objectives can be achieved through the interaction of different resources, including hardware, software, human skills, funds and information resources. To achieve optimal interaction of various resources, system development methodologies are used to develop and deploy information systems in organizations. Therefore, as in the case of all information systems, the development of AIPs should be based on sound system development methodologies, and not ad hoc approaches.

Ad hoc Web development methodologies are not adequate or suitable for the development of sophisticated Web-based information systems such as portals. There are several problems associated with these approaches. When using ad hoc approaches, most Web site and portal developers go directly into the implementation phase of the system, paying little or no attention to requirements acquisition and specification (Coda et al. 1998). This makes it very difficult to successfully develop, deploy and maintain Web sites over the long term and the result is poorly developed Web-based applications that have a high probability of failure (Pressman 2000:18-19). Furthermore, if established methodologies are not used in Web development, advanced Web-based systems face a variety of problems regarding maintenance, scalability, real-time performance, integrity, configuration and content management, and other technical and non-technical issues (Murugesan and Deshpande 
The non-use of formal Web site and portal development approaches also results in poor or inadequate management of Web development projects, leading to a number of problems. For example, the results of a survey by the Cutter Consortium (2000) highlight the following as the major problems plaguing large Web-based projects resulting from inadequate e-project management (any project that involves creating or changing the source code that is deployed on the Internet):

- Delivered systems that do not meet business needs

- Schedule delays

- Projects exceeding the budget

- Delivered systems that do not have the required functionality

- Deliverables that are of poor quality.

The success in developing an AIP project will depend largely upon the effort, care and skill applied in its initial planning, that is, good planning guidelines, which could be used independently of the portal development approach. Therefore, $\mathrm{w}$ ith a current variety of approaches for Web site and portal development to choose from, the guidelines for the deployment of AIPs proposed in this article only address the planning phases of portal development, as established in a major research project for the SADC area (Chisenga 2004).

\subsection{Purpose of the guidelines}

The purpose of the proposed guidelines is to assist agricultural research organizations in the SADC region in particular, and sub-Saharan Africa in general, to conceptualize, plan and manage the deployment of AIPs to serve the needs of agricultural researchers. Based upon the findings of the above-mentioned research project, it can be argued that, in particular, the guidelines should assist agricultural research organizations in the SADC region to:

- Manage the deployment of AIPs

- Set realistic and achievable objectives for the development of AIPs

- Identify the target users for the AIP

- Identify the resources required for the development of AIPs

- Identify the resources, facilities, tools and services to be provided via the AIP

- Understand the desirable features of AIPs

- Be aware of the various possible costs involved in deploying AIPs

- Be aware of the various technologies required for the deployment of AIPs

- Develop suitable AIP implementation strategies

- Consider and adopt suitable AIP development approaches (Chisenga 2004:245).

\subsection{Limitation of the guidelines}

The portal development guidelines proposed in this article are based on the premises that:

- Agricultural research organizations in the SADC region, and in sub-Saharan Africa in general, are at different levels of development regarding access to ICT and other resources such as funding and skilled IT specialists, and therefore there is a need to provide guidelines that could be applicable to different types of agricultural research organizations.

- There are several approaches and methodologies, for example Web development methodologies, software engineering methodologies, Web engineering methodologies, and others that agricultural research organizations could adopt and use in portal development. 
- Different p roprietary, commercial portal development tools (especially those used for developing Enterprise Information Portals) and Open Source tools are available in the market and these could be used for designing, developing and implementing AIPs (Chisenga 2004:246).

The guidelines do not attempt to restrict or limit organizations to one portal development approach or portal development tool, but rather provide a description of the various activities that should be taken into account when planning a portal project. In addition, the guidelines do not cover or propose the actual design of the various features of the portal that could be subject to different preferences by different agricultural research organizations and individual researchers. The guidelines, rather, are independent of specific portal design or development methodology, application domains and techniques.

\subsection{General guidelines}

One of the aims of the extensive research project on potential agricultural portal applications in the SADC region was to divide the guidelines into general and specific categories. The general guidelines were sub-divided in a number of activities that should be conducted to ensure the successful deployment of AIPs (Chisenga 2004:247-257).

From the general guidelines, eight so-called activities were identified. These recommendations were developed from the evaluation of current international Web sites and portals, as well as the empirical findings reported elsewhere (Chisenga and Van Brakel 2004:123-135):

- Activity 1: Setting up the AIP project team

- Activity 2: Definition of AIP goals and objectives

- Activity 3: Inventory and analysis of AIP technical infrastructure

- Activity 4: Definition of the desirable AIP features

- Activity 5: Selection of AIP development approach

- Activity 6: Developing a strategy for AIP adoption

- Activity 7: Budgeting for AIP development costs

- Activity 8: Developing an AIP deployment schedule.

\subsubsection{Activity 1: Setting up the AIP project team}

The development of an AIP should involve various stakeholders from within and outside the organization. In cases where the portal will also interact via an extranet with external users, such as partner agricultural research organizations and interested individuals, there is also a need to involve representatives or obtain the views of major partner organizations. Therefore, as soon as the idea of an AIP is mooted, one of the first activities to be conducted should be the setting up of an AIP project team (AIP-PT) composed of members from the various stakeholders. The main role of the AIP-PT is to plan, document current practices, set-up priorities and co-ordinate the deployment of the portal framework within the organization. The AIP-PT should have a correct mix of information technology specialists, researchers, management staff, information and knowledge management specialists, all working together towards implementing a suitable portal strategy for the organization. The main justification for including various stakeholders on the AIP-PT is that each of the stakeholders brings special expertise and knowledge to the team. This is briefly explained below:

- Agricultural researchers: They are expected to be the main users of the AIP and therefore they should be actively involved in the whole portal project from the onset. Researchers are also content developers and much of the information and knowledge they generate should be integrated into the portal framework. Because of their dual 
role, both as content users and content generators/owners, their participation and input in the portal development process is vital.

- Information technology specialists: An organization's information technology staff (programmers, Webmasters, database administrators, network administrators and many others) should be involved in the portal development process, regardless of the portal development strategy adopted by the organization. Among the members of the proposed portal development project team, information technology specialists are the only ones with the technical know-how regarding the various ICT facilities that could be used in the deployment of the portal in the organization. Therefore, their input into the portal planning process is very useful.

- Information and knowledge management specialists: Agricultural science librarians, documentalists, information and knowledge managers and subject matter specialists should be part of the portal development project team. They possess useful experience, knowledge, information management and organizational skills, which are very relevant and important in the AIP environment.

- Senior management: The participation or representation of senior management would ensure that the deployment of the portal is within the overall objectives of the research organization. In addition, if senior management buys into the idea of providing information services and facilities via a portal, it would ensure that the project is given favourable consideration when it comes to funding the project. A senior member of the management team should, preferably, chair the meetings of the AIP-PT.

- Partner organizations and individuals: To ensure that potential obstacles to information and resource sharing via the portal are addressed in good time, it is important to include representatives of the major partner organizations into the AIPPT. This is necessary when external organizations and individuals (consultants or selected individuals from the general public) are involved and the intention is to allow such organizations and individuals access to the portal facilities via an extranet, and also when some of the resources and services provided by the partner organizations are to be integrated into the portal.

Depending on the size of the organization, in terms of staff and the number of agricultural research stations or institutes, it may also be necessary to establish special interest groups (SIG) or focus groups that would provide input into the activities of the AIP-PT.

\subsubsection{Activity 2: Definition of AIP goals and objectives}

The AIP project should fit into the overall goals and objectives of the organization and, therefore, one major activity that should be conducted by the AIP-PT is to define the goals and objectives of the portal. The goals and objectives of the portal will define what the organization wishes to accomplish with the portal, and also set parameters on the development and accumulation of content on the portal.

The following is an example of what the goal of an agricultural information portal could be:

To provide access to appropriate information resources and services by taking advantage of the available portal technology solutions and facilitate collaboration and sharing of knowledge among researchers in order to enhance the generation, adaptation and transfer of agricultural technologies and knowledge for both subsistence and commercial farmers and other stakeholders for the sustainable development of agriculture.

Examples of the objectives of an agricultural information portal could include the following:

- To gather/bring together content and services from a variety of internal and external 
sources and aggregate them into a single point that can be accessed by researchers

- To provide researchers with access to a variety of information resources and services to support their research work on their desktops, through a single Web-based interface

- To support a single log-on to obtain authentication and authorization of all information resources and applications

- To allow researchers to personalize and customize the presentation of information and services they would like to access on the portal

- To promote collaboration and sharing of data, information and knowledge among researchers

- To improve productivity through quicker access to information resources and knowledge generated within and outside the organization.

In the above context, the success of the portal could then be measured by asking to what extent it meets the above goal and objectives.

\subsubsection{Activity 3: Inventory and analysis of AIP technical infrastructure}

Implementing a portal requires various types of ICT facilities. It is, therefore, important to make an inventory and analysis of the available ICT facilities (do a technology audit) to determine whether the available facilities are adequate for the deployment of a portal environment in the organization, what ICT facilities should be used and, where applicable, to establish which facilities should be replaced or upgraded. Among other things, the inventory and analysis should examine the availability, state and status of the following ICT facilities in the organization:

- Personal computers or laptops: For use by the portal end-users to access the portal resources, add and modify content on the portal, and for use by portal and content developers

- Servers: Different types of servers, both hardware and software. Regarding software, this may include portal application servers providing the development infrastructure for the portal; and Web servers to work with the portal application server to provide the environment for managing client requests

- Application software: Different types of software applications to be used by portal users and individuals involved in the development of the portal

- Database software: Database systems implemented in the organization, for example, Oracle, Microsoft Access, MySQL and others. Portals require the use of a database system to keep track of information specific to the portal, such as users, personalization settings, available portal services and security

- Network infrastructure: The type of LAN available, and whether the organization has a WAN or intranet and extranet in place; availability of Internet connectivity and the type of connectivity available, for example, dial-up, leased-line connection, or a VSAT (very small aperture terminal) connection

- ICT skills: An examination of the capacities available within the organization, in terms of ICT skills, such as staff with computer programming skills, databases administration, and Web site design and development.

\subsubsection{Activity 4: Definition of desirable AIP features}

The AIP-PT should also outline the features that the organization would like to incorporate into the portal. Based on the needs of the major users, an agricultural information portal should incorporate the following features, as identified above:

- Personalization: Researchers should be able to personalize the portal appearance, content and application interface to suit their individual needs, and also to avoid 
unwanted information.

- Organization of the user's desktop: The portal should assist researchers to organize their desktops, to enable them to have access to the most important information content they need.

- Division of resources: The portal should have features that separate facilities into various layers for different categories of users. Portal users should have varying degrees of privileges ranging from researchers, who could add and edit content on the portal, to portal administrators who can modify the configuration of the portal itself. In addition, the portal should also be able to restrict access to selected content, when defined as such. For example, information resources intended for a particular individual or group should be accessed by that individual or group only.

- Tracking of individual usage, interests and use behaviour: The portal should be able to track individual usage, interests and behaviour to make it easier for users to personalize the portal and so that the portal can present a personalized view of the information resources to the user.

- Provision of access to multiple heterogeneous data resources: Users should be provided with access to information from multiple heterogeneous data stores. These could include information from relational databases, multi-dimensional databases, document management systems, e-mail systems, Web servers, news feeds and various file systems or servers.

- Facilities for locating information and people: It should be easy for users to locate colleagues and the information they need, both within and without the organization. There must be ways to both passively discover and actively locate experts, communities and content related to the areas of interest of the researchers.

- User authentication: Portal users should be requested to register and supply their username, password or personal identification number (PIN), before a personalized view of the information resources available on the portal is provided to information end-users known to the portal. Users who have not logged on should only see content meant for the general public.

- Taxonomy: Content on the portal should be organized according to a well-defined classification scheme or taxonomy to facilitate information resource identification, searching and browsing by users.

The above features should be independent of any specific portal development approach. This means that even if the organization opts to develop the portal using in-house resources (insourcing), or to contract an external firm (outsourcing), or to acquire a turnkey portal solution, the above features should be part of the portal solution to be implemented.

\subsubsection{Activity 5: Selection of AIP development approach}

The organization should decide which portal development approach is to be used or adopted. There are several options available, among them the following:

- In-house development (in-sourcing): The organization may choose to build the portal using its IT staff and the many available free open-source software and tools. However, this option requires technical expertise, especially programmers, and resources such as time and equipment, some of which are generally not available in most public-funded agricultural research organizations in Africa. In addition, documentation for open-source software is not always as good as commercial software, and if IT staff in the organization have no experience with the open-source software selected for the project, they may take longer to learn and master the software.

- Commercial portal development software: Purchase and use of commercial portal development software is another option available to agricultural research 
organizations. However, although there are several off-the-shelf portal development software packages that could be used, most of them would require customization and this could result in additional costs. The cost of some software may also be prohibitive. In some cases, available information resources within the organization may also need to be migrated to the new software platform, resulting in additional costs.

- Outsourcing portal development: There are several firms involved in portal development that could be contracted to do the job. This approach could be cost effective and less time consuming. However, use of an external firm may make the organization dependent on the firm for maintenance and technical support, resulting in additional costs. The consulting firm or individual may also bring into the organization their preferences in terms of portal development approach and hardware and software that may not be compatible with the requirements of the organization. In addition, dependence on external firms could result in the organization not developing the required local capacities necessary for sustaining the portal.

In the final analysis, organizations should select a portal development approach that will deliver the required portal on time and within the organization's budget, while incorporating the above features.

\subsubsection{Activity 6: Developing a strategy for adopting AIP}

The success of the deployment of the portal within the organization will depend on how far it is accepted and used by the stakeholders (senior management, portal project champions, content providers, researchers and other partners). Therefore, a strategy should be put in place, from the onset, to stimulate and encourage the support and adoption of the portal at all levels within the organization or among the stakeholders. Senior management should be encouraged to buy into the idea of the portal, and provide strong support and advocacy for the adoption of the portal within the organization. Without the involvement of senior management, adoption of the portal at departmental and user levels would be difficult. The main potential portal users should also be encouraged to integrate the portal into their work activities.

\subsubsection{Activity 7: Budgeting for AIP development costs}

Whether an organization opts for the development of the portal in-house, using internal expertise, or contracts a firm or individual consultant, or decides to purchase off-the-shelf portal development software, there are costs to be met. It is, therefore, important to include a budget for the development and deployment of the portal in the overall planning portal deployment strategy. The costs will vary depending on the scope of the portal project, the features to be incorporated into the portal, and the portal development approach that is adopted. Overall, the costs may include the following:

- Hardware costs: Purchase, installation and maintenance of new or additional hardware, such as servers, to facilitate the development and implementation of the portal; and upgrading of existing hardware facilities, if required.

- Software costs: Purchase of portal development software, database software and annual software licences, maintenance and support, and upgrading of existing software facilities, if required.

- Networking and connectivity costs: If the organization does not have a local area network in place, this has to be installed and network administrators hired. In addition, the organization should deploy an intranet, if it is not already in place, and an extranet if required, and establish Internet connectivity if this is not already available.

- Costs for migrating content: Old content and databases will probably have to be migrated to the new portal environment. 
- Training costs: Training of IT staff in the use of new technologies to be used in the development of the portal, individuals to be involved in the various aspects of managing the portal, individuals (data owners) who will be contributing content to the portal, and portal end-users (researchers) in the use of the portal.

- Personnel costs: These include costs for hiring new staff with skills that may be currently absent in the organizations but necessary for the successful deployment of the portal, hiring of external expertise (firms or individuals) to assist with portal development, content development, knowledge management and integration.

\subsubsection{Activity 8: Development an AIP deployment schedule}

The AIP-PT should develop a schedule for the development and deployment of the portal within the organization. During interviews with a number of people in organizations in the United Kingdom who were involved in the development of Web-based applications, McDonald and Welland (2001) found that Web applications had a very short development life-cycle. In general, this was no longer than six months, while the average development life-cycle time of a Web application was observed to be just under three months. The AIP-PT should take this into account when developing the schedule.

\subsection{Specific guidelines}

Specific guidelines were derived from the components of the AIP illustrated in Figure 1 above (Chisenga 2004:257-266). These include:

- End-users

- Content and services

- Developers

- Content developers and sources of content

- Development tools

- Content publishing and management tools

- Content management and use policy

- User training and support

- User tools

- Information discovery tools

- Security

- Integration with the Internet.

\subsubsection{Portal end-users}

An AIP should be designed with the users in mind. It should be owned and managed by the users. Therefore, all potential portal end-users in the organization should be identified and categorized. They should be consulted and involved in the major decisions about the portal. Issues relating to the ownership and management of the portal should also be discussed with the portal users.

A decision should be made on whether the portal will serve all categories of staff within the research organization or only selected groups of staff, for example, researchers. In addition, the following factors that are likely to have an impact on the portal end-users' ability to use the portal-based resources and facilities should be addressed:

- Access to appropriate ICT facilities at the office and home

- Level of ICT skills.

If the target portal end-users do not have access to appropriate ICT facilities or their ICT use 
skills are very low, the adoption and acceptance of the portal in the organization is likely to be affected. Access to ICT facilities at home, such as personal computers, laptops and the Internet, especially the Web, could lead to users requesting access to the portal from their homes.

\subsubsection{Portal content and services}

An AIP is an aggregation of several different information resources, services, tools and facilities to be provided to the user community. Therefore, the content for the AIP, where possible and necessary, should also include structured data sources such as relational databases and data warehouses, unstructured content sources such as news, documents generated inside the organization and external sources such as public or private Web sites, documents and Web-based services.

Resources, services and facilities to be provided via an AIP should be identified through an information audit that should establish the following:

- Information resources generated within the organization, and their structure

- Information resources and services obtained from outside the organization

- Frequency of use of information within the organization

- Users of information and the type of information used

- How the information is used

- Software and other software-based tools used in the organization, and their users

- Flow of information within, into and outside the organization

- Areas for improvement regarding the generation and management of information content within the organization.

The information audit activity should also identify the information resources, including documents, Web content, databases - both bibliographic and full-text - application software and tools that individual researchers and groups need to access the portal to do their work (information needs assessment). It should also document the work-flow within the organization, and see how this could be implemented within a portal-based environment. Finally, the following categorizations, based on various factors such as the targeted end-users of the portal, should be made regarding the possible content of the portal:

- Personal content: Information, resources, tools and applications required by specific individual researchers

- Workgroup content: Information, resources, tools and applications required by different groups or individuals, for example by departments and researchers collaborating on projects

- Intranet/corporate content: Information, resources, tools and applications required by most portal end-users generated within the organization, that is, information regarding research funding and guidelines for research proposals

- Extranet content: Information, resources, tools and applications required from other partner organizations or other research stations or institutes, to be provided to authorized external users

- External/Internet content: Information, resources and tools such as Web sites, Internet search engines and many more from the Internet.

The organization of the portal contents, services and facilities should reflect the users' interests rather than the needs of the organization.

\subsubsection{Portal developers}


Depending on the size and sophistication of the AIP, its development and deployment would require various types of technical skills, among them the following:

- Programming skills in various languages and scripts used in portal development, for example Perl, CGI, HTML, Visual Basic, Java, JavaScript, PHP, C++, XML

- Network administration, including TCP/IP administration

- Internet, intranet and extranet administration

- Database development and administration, for example MySQL and Oracle

- Operating systems, for example Linux, UNIX and Windows 2000

- Information management

- Project management

- Creative designing.

An organization should make an effort to find staff with the correct mix of the above skills. Unfortunately, it is most unlikely that agricultural research organizations will have staff with all of the above skills. In cases where the required skills are not available, it may be necessary to outsource the development of the portal, or some parts of the portal.

\subsubsection{Portal content developers and sources of content}

A portal should provide access to useful content, services and facilities. Therefore, all the potential sources of content, both from within and without the organization, should be identified. These may include the following:

- Individual researchers or departments within the organization

- Partner research organizations

- Relevant government ministries and departments, for example the Ministry of Agriculture, and other related ministries, for example those for fisheries and rural development

- Academic institutions such as universities or colleges of agriculture, and their libraries

- International agricultural organizations that are involved in the generation and provision of access to agricultural information

- Organizations involved in funding agricultural research and related projects, for example the World Bank and the Department for International Development (DFID) of the UK government.

The identification of content developers and external sources of content should include identification of content that will be acquired free of charge and that which will be paid for. The cost of acquiring external content for the portal should also be included in the budget.

\subsubsection{Portal development tools}

Web site and portal development require the use of different types of software-based tools. There are two main options available to organizations, namely the use of proprietary software or open-source, software-based development tools.

Proprietary or commercial portal development tools/software (especially for enterprise information portals) available on the market could be used to design, develop and implement an AIP. These include products such as WebSphere Portal by IBM, CleverPath Portal by Computer Associates International, Microsoft SharePoint Portal Server 2003, Oracle9i Application Server Portal by Oracle, and many others. In addition, organizations could opt for open-source portal technology solutions such as Jetspeed (an open-source implementation of an enterprise information portal), Metadot Portal Server, and Zope (an open-source application server and portal toolkit) and tools/software like MySQL, Linux, 
PHP (hypertext preprocessor), Perl and many others.

Organizations should identify and list all the tools that would be required, find out which tools are already available within the organizations, and which ones will have to be acquired.

\subsubsection{Portal content publishing and management tools and guidelines}

Individuals and departments within the organization involved in content development should be provided with various tools, especially content management software, to assist them in their work. Using content management systems, they should easily be able to generate content, edit (proof read) and publish on the portal. The content management system should provide facilities and features to deal with documents in their original formats, such as Microsoft Word, Microsoft Excel, Portable Document Format (PDF) and others. It should also include Web editing features such as page templates and wizards, HTML editors, and XML editors to allow content developers to author Web content.

It is important to develop content publishing guidelines and standards to assist content developers in creating and publishing content on the portal. Content developers need to know what content should be published or not published on the portal, and when to update or remove the content.

\subsubsection{Portal content management policy}

The organization should put in place a content management policy to support and facilitate the process of authoring, contributing, reviewing, modifying, approving, publishing, delivering and maintaining digital content integrated with or accessed via the AIP. In addition, the content management policy should empower researchers and agricultural information specialists to manage the content on the portal, while the information technology specialists within the organization should concentrate on managing the portal's technical infrastructure. The portal content should preferably be hosted on the organization's own computer servers. If hosted on an external server, the organization should have the ability to change the content at will.

\subsubsection{Portal user training and support}

All categories of portal users should be empowered through training so that they can access and use the portal facilities effectively. Training can take the form of workshops, seminars and online courses accessed via the portal. In addition to training, user support should be provided. This can be in the form of access to a physical help desk or an online help desk, online tutorials, telephone support and access to lists of frequently asked questions (FAQs). Training should be a continuous process.

\subsubsection{Portal user tools}

When planning the deployment of an AIP, decisions should be made regarding the types of tools to be used on the portal and these tools should be configured, packaged and tested together. According to CIO Communication (2001), providing users with tested, packages, licensed tools will reduce the amount of time required for support. Support also simplifies the update process, reduces the amount of training and documentation, and makes it easier for new users to become familiar with the portal.

Depending on the various requirements, the tools provided may include the following:

- Web browsers: Microsoft Internet Explorer, Navigator or Opera 
- Plug-ins: Microsoft Media Player, Real Player, QuickTime Player, Adobe Acrobat Reader

- Specialized software: For example, Microsoft Office Suite and Lotus Smart Suite.

\subsubsection{Portal information discovery tools}

Portal users should have access to various information discovery tools. Provision of information discovery tools on the portal will ensure that the portal resources are visible and reduce the time users spend on searching for information. The tools may include a combination of the following:

- Consistent page navigation aids and local search engines

- Search directories

- Push technologies

- Information specialists.

\subsubsection{Portal security}

As more organization content becomes accessible via the portal, and especially if external users are also allowed to access some of the content on the portal via an extranet or the Internet, security will become a critical issue. The organization should, therefore, plan and integrate the portal's security services into its overall security infrastructure. Portal security should include both guarding against un-authorized access to the portal and against unauthorized access to portal resources and services once access to the portal is allowed. Decisions should be made regarding the following:

- Which individual users or user groups will have access to the portal?

- Which individual users or user groups will have privileges to add, modify or delete content of the portal?

- Which individual users or user groups will have privileges to modify the appearance of the content area?

- What resources and services on the portal will be accessed by which user groups?

In addition, security regarding access to the rooms where the equipment hosting the portal server software and content are stored should also be implemented.

\subsubsection{Portal integration with the Web}

The Internet, especially the World-Wide Web, is a major source of information in digital format. Organizations can pull various resources from the Web, using software tools and information specialists, and integrate them into the local resources. To take advantage of Web resources, it is important that an AIP supporting research activities of the organization is integrated with the Internet.

Portal integration with the Internet should also include integrating with the organization's email system. Agricultural research organizations should plan in advance how to manage and integrate the e-mail communication system into the portal environment. As more and more researchers adopt the use of e-mail for their communication and sharing of research results within the organization, the system will become an important source of content for the portal. It is, therefore, necessary to save key and important e-mails messages in much the same way that organizations traditionally maintained paper files. 


\section{Conclusion}

Use of portals in agricultural research organizations in the SADC countries would definitely improve the access and utilization of relevant information resources according to the information needs of researchers. However, development of such portals should be based on sound information system development approaches, and the guidelines proposed in this article should ensure that organizations adhere to a well-structured approach to portal development.

\section{References}

Berkman, E. 2000. What is a portal? [Online]. Available WWW: http://www.darwinism.com/read/120100/portal_curve_content.htm(Accessed 7 February 2001).

Besemer, H., Addison, C., and Ferguson, J. 2003. Fertile ground: opportunities for greater coherence in agricultural information systems. [Research Report no. 19, December 2003].

Chisenga, J. 2004. Application possibilities of agricultural information portals. Unpublished doctoral thesis. Johannesburg: Rand Afrikaans University.

Chisenga, J. and Van Brakel, P.A. 2004. Content on agricultural research organisation Web sites: a study of international trends. Libri 54(2):123-135.

CIO Communications. 2001. An Intranet reference model. [Online]. Available WWW: http://www.cio.com/research/intranet/refmodel/index.html (Accessed 27 October 2001).

Coda, F. et al. 1998. Towards a software engineering approach to Web site development. [Online]. Available WWW:

http://www.cs.ucsb.edu/ vigna/pub/1998_coda_ghezzi_vigna_garzotto_iwssd98.pdf (Accessed 29 January 2004).

CNET Networks. 1999. Looking at Web portals: types of portals. [Online]. Available WWW:

http://builder.cnet.com/webbuilding/pages/Business/Portal/ss01.html (Accessed 20 December 2001).

Cutter Consortium. 2000. Poor project management number-one problem of outsourced eprojects. Research Briefs, 7 November 2000. [Online]. Available WWW: http://www.cutter.com/research/2000/crb001107.html (Accessed 14 January 2004).

Ethridge, R.R., Hadden, C.M. and Smith, M.P. 2000. Building a personalised education portal: get a behind-the-scenes look at LSU's award winning system. EDUCASE Quarterly 3:12-19.

Hu, J. 1999. Publisher launches a Web site for disabled. CNET News.Com December 3, [Online]. Available WWW: http://news.com.com/2100-1023-233905.html?legacy=cnet (Accessed 11 March 2002).

Hurwitz, J.S. 2001. Portals tie problems to solutions. InformationWeek (820):110. 
McDonald, A. and Welland, R. 2001. Web engineering in practice. [Online]. Available WWW: http://www.dcs.gla.ac.uk/ andrew/webe2001.pdf (Accessed 14 January 2004).

Morrison, D. 2000. Building successful portals. [Online]. Available WWW:

http://www.tcin.com/ebs.nsf/d83de8b348e854acc12568970075c66b

10c3d7772ec6e5e3dc12568e4006bb1f6! OpenDocument (Accessed 7 February 2001).

Morrison, D., Buckely, M. and Cappo, S. 1999. Building a portal with Lotus Domino R5. Austin, Texas: IBM.

Murugesan, S. and Deshpande, Y. 2000. Workshop 2: Web engineering: a new discipline poised for rapid growth. [Online]. Available WWW:

http://www.ul.ie/ icse2000/wow/issue1/webengworkshopreport.htm (Accessed 23 August 2002).

O'Leary, M. 2000. Grading the library portals. Online (November). [Online]. Available WWW: http://www.onlinemag.net/OL2000/oleary11.html (Accessed 13 March 2002).

Pressman, R.S. 2000. What a tangled Web we weave. IEEE Software (January/February):1821.

Rowley, J. 2000. Portal power. Managing Information 7(1):62-64.

Webopedia 2001. Web portals. [Online]. Available WWW:

http://www.webopedia.com/TERM/W/Web_portal.html (Accessed 24 December 2001).

\section{Disclaimer}

Articles published in SAJIM are the opinions of the authors and do not necessarily reflect the opinion of the Editor, Board, Publisher, Webmaster or the Rand Afrikaans University. The user hereby waives any claim he/she/they may have or acquire against the publisher, its suppliers, licensees and sub licensees and indemnifies all said persons from any claims, lawsuits, proceedings, costs, special, incidental, consequential or indirect damages, including damages for loss of profits, loss of business or downtime arising out of or relating to the user's use of the Website.

Published by InterWord Communications for the Centre for Research in Web-based Applications, Rand Afrikaans University 